\title{
THE EFFECT OF INCREMENTAL CONFINING PRESSURE ON THE HYDRAULIC PROPERTIES OF PVD
}

\author{
*Galuh Chrismaningwang ${ }^{1,2}$, Hary Christady Hardiyatmo ${ }^{1}$, Agus Darmawan Adi $^{1}$ and Teuku Faisal \\ Fathani $^{1,3}$ \\ ${ }^{1}$ Faculty of Engineering, Universitas Gadjah Mada, Indonesia \\ ${ }^{2}$ Faculty of Engineering, Universitas Sebelas Maret, Indonesia \\ ${ }^{3}$ Center for Disaster Mitigation and Technological Innovation (GAMA-InaTEK), Universitas Gadjah \\ Mada, Indonesia
}

*Corresponding Author, Received: 02 March 2020, Revised: 23 March 2020, Accepted: 07 April 2020

\begin{abstract}
Prefabricated Vertical Drains (PVD) has become a standard method in soft soil improvements project to accelerate the soil consolidation time. Due to PVD's primary function as drainage, it should have adequate hydraulic properties, i.e., discharge capacity and transmissivity. This paper evaluates the effect of incremental confining pressure on three types of PVD using an apparatus adopting ASTM D4716, a mechanism to determine the in-plane flow rate and transmissivity of geosynthetics. The apparatus is originally designed to observe the discharge capacity of the PVD. Three types of PVD with different thickness and box channel core shapes were tested under incremental confining pressure in the range of 50 to $200 \mathrm{kPa}$ and varied hydraulic gradients. The results indicated that the reduction of discharge capacity under incremental confining pressure is higher for lower hydraulic gradients, and the reduction of discharge capacity is significant at high confining pressure. The thickness of PVD held an essential role in transmissivity since PVD with greater thickness provides higher discharge capacity and transmissivity.
\end{abstract}

Keywords: Discharge capacity, Transmissivity, Hydraulic Gradient, Geosynthetic drain

\section{INTRODUCTION}

Prefabricated Vertical Drains (PVD) is a popular method to accelerate consolidation time in soft soil by reducing the length of the drainage path so that the excess pore water can dissipate in a shorter time. This method has popularly worked as a replacement for the traditional vertical sand drains method. PVD had extensively implemented in soft soil improvement and land reclamation projects [15], also considered as the most cost-effective technique [6]. PVD is often used alone, or in combination with PHD and surcharge pre-loading [7] to speed up the consolidation time, sometimes it is also used in combination with vacuum preloading [8].

Since the primary function of PVD is for drainage, it must have adequate hydraulic properties to work efficiently [9]. The most important hydraulic properties are discharge capacity $\left(q_{w}\right)$ and transmissivity $(\theta)$ since they represent the performance of PVD [10]. Indeed PVD should have sufficient value of discharge capacity to be able to work effectively.

Discharge capacity and transmissivity are affected by the following factors: available drainage channel area, lateral earth pressure, deformations of the drain due to settlement, and infiltration of soft soil particles, which can lead to clogging [11]. Researches on the influence of confining pressure and deformation on PVD were comprehensively conducted [6,7]. Several methods to measure discharge capacity in the laboratory using various apparatus have been introduced [11-14].

This paper presents the effect of incremental confining pressure and hydraulic gradients on PVD, in which the data was collected by laboratory measurements using a newly designed apparatus. This apparatus is designed initially to observe the discharge capacity of the PVD. ASTM D4716 is adopted to design the apparatus. This method can evaluate the effect of confining pressure on the drains under a constant head flow and indirectly determined the discharge capacity, transmissivity, as well as the in-plane permeability value [17].

\section{HYDRAULIC PROPERTIES OF PVD}

\subsection{Discharge Capacity}

Discharge capacity $\left(q_{w}\right)$ is described as the volume of water per unit time that can be conducted under a unit hydraulic gradient in the drain core in axial directions [18], which is defined as follows :

$$
\begin{aligned}
& q_{w}=\frac{Q}{i} \\
& i=\frac{\Delta h}{L}
\end{aligned}
$$


where, $Q$ is the rate of water flow per unit of time $\left(\mathrm{m}^{3} / \mathrm{s}\right), i$ is the dimensionless hydraulic gradient, $\Delta h$ is the head difference $(\mathrm{m})$, and $L$ is the drainage flow length (m). In this study, $L$ is defined as the length of the specimen.

\section{$2.2 \quad$ Transmissivity and In-plane Permeability}

The transmissivity of PVD is determined as the capability of water to flow in the parallel direction to the plane of the specimen. Eq. (3) is used to calculate the value of transmissivity, $\theta[17]$.

$\theta=\frac{Q L}{w \Delta h}$

where, $w$ is the specimen width (m). Eq. (4) shows that transmissivity is subjected to in-plane permeability and geosynthetic thickness [19].

$\theta=k t$

where, $k$ is the in-plane permeability, and $t$ is the thickness of PVD.

Generally, transmissivity decreases when the confining pressure and hydraulic gradient increase, since the thickness of PVD decreases when subjected to confining pressure. The relationship between transmissivity and thickness is proposed by [20], as shown in Eq. (5).

$$
\frac{\theta_{1}}{\theta_{2}}=\left[\frac{t_{2}-\frac{\mu}{\rho}}{t_{1}-\frac{\mu}{\rho}}\right]^{3}
$$

where, $\theta_{1}$ is the transmissivity of PVD when the thickness is $t_{1}, \theta_{2}$ is the transmissivity of PVD when the thickness is $t_{2}, \mu$ is mass per unit area $\left(\mathrm{kg} / \mathrm{m}^{2}\right)$, and $\rho$ is polymer density $\left(\mathrm{kg} / \mathrm{m}^{3}\right)$. The value of $\frac{\mu}{\rho}$ is constant for the same type of PVD. Thus, it is not affected by thickness reduction.

\section{RESEARCH METHODS}

\subsection{The Structure of PVD}

PVD is a geocomposite that consists of two main components; filter and core. The core has a function as a drainage channel since the filter is used to protect and separate the core from the surrounding soil. Generally, PVD was manufactured from hydrophobic polymers, such as polypropylene, polyester, polyethylene, etc. [21].
The structure of the PVD used in this study is presented in Fig. 1, with the thickness and the width of PVD, are defined as $t$ and $b$, respectively. This research observed three types of PVD, namely, PVD-T3, PVD-T4, and PVD-T5 for the thickness of 3 , 4, and $5 \mathrm{~mm}$, respectively. All samples have non-woven and heat-bonded filters, also have box channel type core.

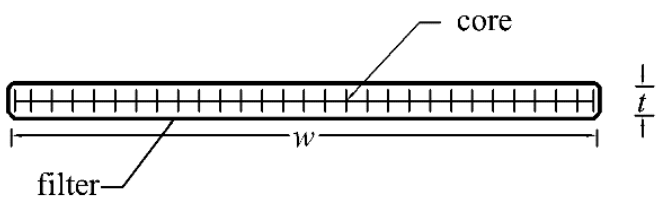

Fig.1 Cross-section of PVD

The properties of PVD materials are presented in Table 1. The dimension of the PVD was determined using ASTM D 5199-99 [22], along with the mass per unit area and polymer density was measured following ASTM D 5261-92 [23].

Table 1 Physical properties of PVD

\begin{tabular}{lccc}
\hline \multicolumn{1}{c}{ Properties } & PVD-T3 & PVD-T4 & PVD-T5 \\
\hline $\begin{array}{l}\text { Thickness, } t \\
(\mathrm{~mm})\end{array}$ & 3 & 4 & 5 \\
$\begin{array}{l}\text { Width, } w(\mathrm{~mm}) \\
\text { Core material }\end{array}$ & 100 & 100 & 100 \\
$\begin{array}{l}\text { Filter thickness } \\
(\mathrm{mm})\end{array}$ & $0.24-0.25$ & $0.24-0.25$ & $0.24-0.25$ \\
$\begin{array}{l}\text { Filter material } \\
\text { Mass per unit }\end{array}$ & PET & PET & PET \\
$\begin{array}{l}\text { area, } \mu\left(\mathrm{kg} / \mathrm{m}^{2}\right) \\
\text { Polymer }\end{array}$ & 898.48 & 0.52 & 0.62 \\
$\begin{array}{l}\text { density, } \rho \\
\left(\mathrm{kg} / \mathrm{m}^{3}\right)\end{array}$ & & 898.54 & 898.54 \\
\hline Note: PP = Polypropylene & & \\
PET $=$ Polyethylene terephthalate &
\end{tabular}

\subsection{Test Apparatus and Methods}

All of the hydraulic properties observed in this study were tested by following ASTM D4716 method [17]. ASTM D4716 is a method to measure the in-plane flow rate and transmissivity of geosynthetics. The test apparatus aimed to measure the discharge capacity of the PVD-PHD connection system, which primarily consists of two main parts; the cylinder compression chamber and the upper compression chamber.

The cylinder compression chamber was designed to test the hydraulic properties of PVD. It consists of an acrylic cylinder with a diameter of $200 \mathrm{~mm}$ and a height of $500 \mathrm{~mm}$, and two PVD holders made from aluminum, which can accommodate a $100 \mathrm{~mm}$ width specimens, with a 5 
mm maximum thickness and a $500 \mathrm{~mm}$ maximum length. The cell pressure in this chamber was applied using a constant pressure device.

The upper compression chamber was originally designed to test the PVD-PHD connection system, but this study only considering the hydraulic properties of PVD, so the upper compression chamber used as an outflow tank to accommodate the water discharge of PVD. This chamber was made from $10 \mathrm{~mm}$ thick steel plates with $500 \times 500$ $\times 700 \mathrm{~mm}$ dimension. The confining pressure for this chamber was designed to use a CBR test device completed with a proving ring. As this study only discusses PVD, the confining pressure did not apply in the upper chamber. The head difference was determined by adjusting the inlet tank. The schematic layout of the apparatus is shown in Fig. 2, and the detail of the PVD holder is shown in Fig. 3.

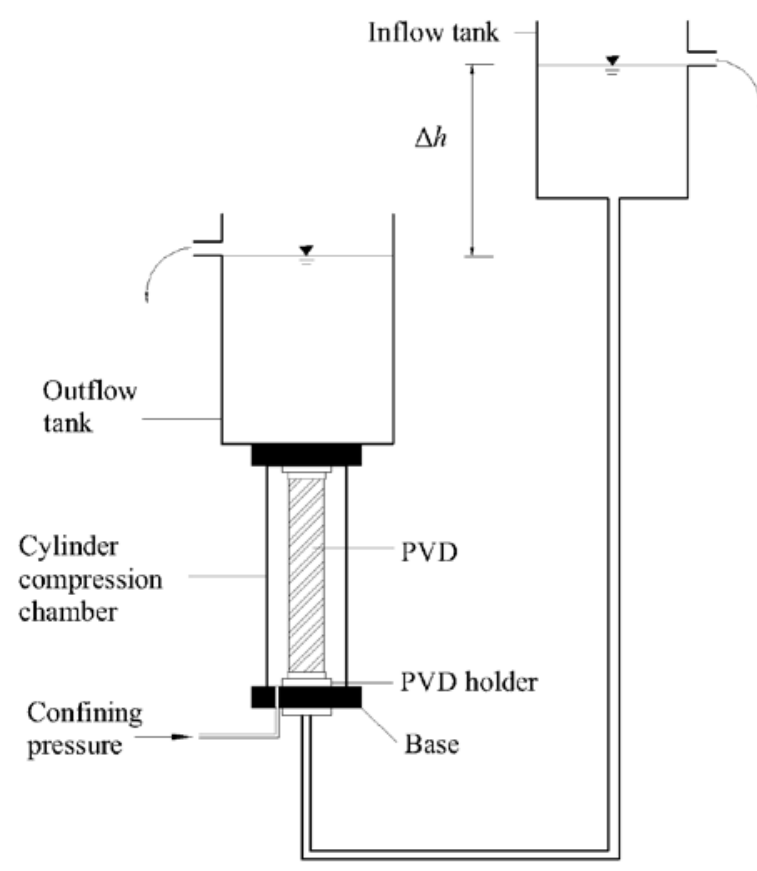

Fig.2 Schematic layout of the apparatus
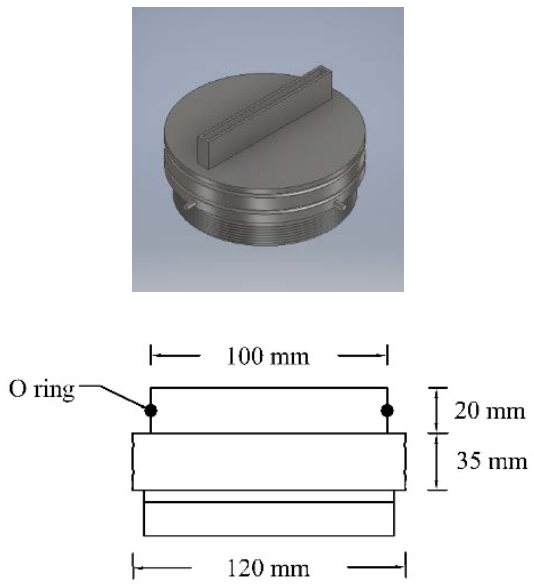

Fig.3 Detail of PVD holder

All tests were conducted on $500 \mathrm{~mm}$ length specimens. In order to separate the specimens from confining water, all specimens were wrapped with a latex membrane. As reported by [24], the discharge capacity of PVD is affected by more than $150 \mathrm{kPa}$ soil lateral pressure. This study used 50 to $200 \mathrm{kPa}$ incremental confining pressure, with a 50 $\mathrm{kPa}$ pressure addition for each stage, the confining pressure value was chosen to represent the lateral earth pressure at a depth of 5 to $30 \mathrm{~m}$, assuming the lateral earth pressure coefficient value is 0.5 . Previously the specimens were subjected to a 20 $\mathrm{kPa}$ confining pressure to evaluate the PVD initial rate of water flow, assuming that the thickness of PVD had not been affected at the stage.

Based on earlier researches, laboratory measurements of hydraulic properties should be carried out with the value of the hydraulic gradients close to field conditions [15]. In order to maintain the laminar flow within the PVD, hydraulic gradients value between 0.1 and 0.3 is recommended [25]. On the other hand, [10] stated that the hydraulic gradient of 0.5 was advised to be used in laboratory measurement of discharge capacity. This study applied the head difference of $0.2,0.4,0.5$, and $1 \mathrm{~m}$ to observe the effect of hydraulic gradients on discharge capacity thoroughly. The average water flow rate was determined by measuring the water discharge through the drains under incremental vertical pressure with constant hydraulic gradients under 15 minutes seating period.

Calibration is required to measure the head loss within the apparatus [26]. The calibration was conducted by allowing the water to flow through a hollow column under varied head difference. The relationship between flow rates $(Q)$ and calibrated head difference $\left(\Delta h_{\text {cal }}\right)$ for the test is plotted in Fig. 4 . The curve is used to determine the corrected hydraulic gradients $\left(i_{\text {corr }}\right)$. The headloss within the apparatus is calculated by subtracting the head difference used in the test $(\Delta h)$ with $\Delta h_{\text {cal }}$, which obtained from Fig.4. The corrected hydraulic gradients $\left(i_{\text {corr }}\right)$ from all specimens were determined by Eq. (6) proposed by [26].

$i_{\text {corr }}=\frac{\Delta h-\Delta h_{c a l}}{L}$

The values of $i_{\text {corr }}$ for each specimen with $L=500$ $\mathrm{mm}$ are presented in Table 2 . Table 2 shows that the The values of $\Delta h_{\text {cal }}$ are particularly small, indicated that the apparatus has a very small effect on the water flow inside the specimens. It can be confirmed that the apparatus is reliable as a test device. 


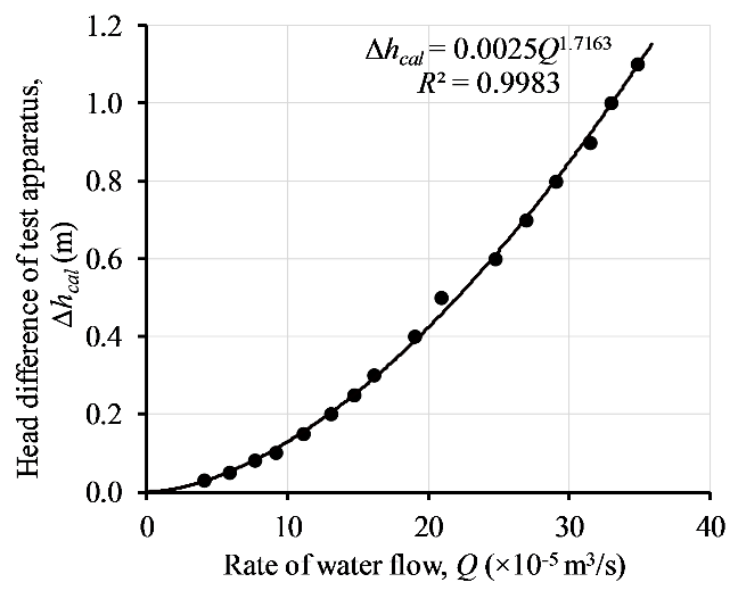

Fig.4 Relationship between the rate of water flow and head difference within the apparatus

\section{RESULTS AND DISCUSSIONS}

Table 2 Values of corrected hydraulic gradient, $i_{\text {corr }}$

\subsection{Influence of Incremental Confining Pressure on Discharge Capacity}

Fig. 5 shows the decrease in the discharge capacity of PVD with incremental confining pressure. The value of discharge capacity was obtained by using Eq. (1). Based on the test results, an identical patterns were found for all of the PVD specimens, as the confining pressure gradually increased from 20 to $200 \mathrm{kPa}$, the discharge capacity decreased linearly. The reduction of discharge capacity under incremental confining pressure is more significant for lower hydraulic gradients. This result is in line with the theory proposed by [13].

All of the specimens have the highest value of discharge capacity reduction that occurred under $\mathrm{i}=$ 0.2 , which is the lowest hydraulic gradient used in this study. The values of the highest discharge capacity reduction for the PVD-T3, PVD-T4, and PVD-T5 under the confining pressure applied from 20 to $200 \mathrm{kPa}$ are $75.71 \%$, 56.93\%, and $45.25 \%$, respectively.

(a) PVD-T3

\begin{tabular}{ccccccccc}
\hline \multirow{2}{*}{$\begin{array}{c}\Delta h \\
(\mathrm{~m})\end{array}$} & \multicolumn{7}{c}{ Confining pressure, $\sigma(\mathrm{kPa})$} \\
\cline { 2 - 8 } & $\Delta h_{\text {cal }}(\mathrm{m})$ & $i_{\text {corr }}$ & $\Delta h_{\text {cal }}(\mathrm{m})$ & $i_{\text {corr }}$ & $\Delta h_{\text {cal }}(\mathrm{m})$ & $i_{\text {corr }}$ & $\Delta h_{\text {cal }}(\mathrm{m})$ & $i_{\text {corr }}$ \\
\hline 0.50 & $5.78 \times 10^{-10}$ & 1.00 & $2.02 \times 10^{-10}$ & 1.00 & $1.90 \times 10^{-10}$ & 1.00 & $1.02 \times 10^{-10}$ & 1.00 \\
0.25 & $2.75 \times 10^{-10}$ & 0.50 & $1.08 \times 10^{-10}$ & 0.50 & $5.94 \times 10^{-11}$ & 0.50 & $3.60 \times 10^{-11}$ & 0.50 \\
0.20 & $2.38 \times 10^{-10}$ & 0.40 & $7.65 \times 10^{-11}$ & 0.40 & $4.16 \times 10^{-11}$ & 0.40 & $2.58 \times 10^{-11}$ & 0.40 \\
0.10 & $9.70 \times 10^{-11}$ & 0.20 & $2.60 \times 10^{-11}$ & 0.20 & $1.59 \times 10^{-11}$ & 0.20 & $8.88 \times 10^{-12}$ & 0.20 \\
\hline
\end{tabular}

(b) PVD-T4

\begin{tabular}{|c|c|c|c|c|c|c|c|c|}
\hline \multirow{3}{*}{$\begin{array}{c}\Delta h \\
(\mathrm{~m})\end{array}$} & \multicolumn{8}{|c|}{ Confining pressure, $\sigma(\mathrm{kPa})$} \\
\hline & \multicolumn{2}{|l|}{50} & \multicolumn{2}{|c|}{100} & \multicolumn{2}{|c|}{150} & \multicolumn{2}{|c|}{200} \\
\hline & $\Delta h_{c a l}(\mathrm{~m})$ & $i_{\text {corr }}$ & $\Delta h_{\text {cal }}(\mathrm{m})$ & $i_{\text {corr }}$ & $\Delta h_{c a l}(\mathrm{~m})$ & $i_{\text {corr }}$ & $\Delta h_{c a l}(\mathrm{~m})$ & $i_{\text {corr }}$ \\
\hline 0.50 & $3.64 \times 10^{-10}$ & 1.00 & $3.29 \times 10^{-10}$ & 1.00 & $2.74 \times 10^{-10}$ & 1.00 & $2.26 \times 10^{-10}$ & 1.00 \\
\hline 0.25 & $1.52 \times 10^{-10}$ & 0.50 & $1.38 \times 10^{-10}$ & 0.50 & $1.13 \times 10^{-10}$ & 0.50 & $9.85 \times 10^{-11}$ & 0.50 \\
\hline 0.20 & $1.20 \times 10^{-10}$ & 0.40 & $1.03 \times 10^{-10}$ & 0.40 & $8.19 \times 10^{-11}$ & 0.40 & $6.97 \times 10^{-11}$ & 0.40 \\
\hline 0.10 & $4.38 \times 10^{-11}$ & 0.20 & $3.62 \times 10^{-11}$ & 0.20 & $2.84 \times 10^{-11}$ & 0.20 & $2.30 \times 10^{-11}$ & 0.20 \\
\hline
\end{tabular}

(c) PVD-T5

\begin{tabular}{ccccccccc}
\hline \multirow{2}{*}{$\begin{array}{c}\text { C } \\
(\mathrm{m})\end{array}$} & \multicolumn{7}{c}{ Confining pressure, $\sigma(\mathrm{kPa})$} \\
\cline { 2 - 8 } & $\Delta h_{\text {cal }}(\mathrm{m})$ & $i_{\text {corr }}$ & $\Delta h_{\text {cal }}(\mathrm{m})$ & $i_{\text {corr }}$ & $\Delta h_{\text {cal }}(\mathrm{m})$ & $i_{\text {corr }}$ & $\Delta h_{\text {cal }}(\mathrm{m})$ & $i_{\text {corr }}$ \\
\hline 0.50 & $5.78 \times 10^{-10}$ & 1.00 & $5.41 \times 10^{-10}$ & 1.00 & $5.18 \times 10^{-10}$ & 1.00 & $4.48 \times 10^{-10}$ & 1.00 \\
0.25 & $2.75 \times 10^{-10}$ & 0.50 & $2.58 \times 10^{-10}$ & 0.50 & $2.36 \times 10^{-10}$ & 0.50 & $1.99 \times 10^{-10}$ & 0.50 \\
0.20 & $2.38 \times 10^{-10}$ & 0.40 & $2.35 \times 10^{-10}$ & 0.40 & $2.08 \times 10^{-10}$ & 0.40 & $1.74 \times 10^{-10}$ & 0.40 \\
0.10 & $9.70 \times 10^{-11}$ & 0.20 & $8.69 \times 10^{-11}$ & 0.20 & $7.67 \times 10^{-11}$ & 0.20 & $6.59 \times 10^{-11}$ & 0.20 \\
\hline
\end{tabular}




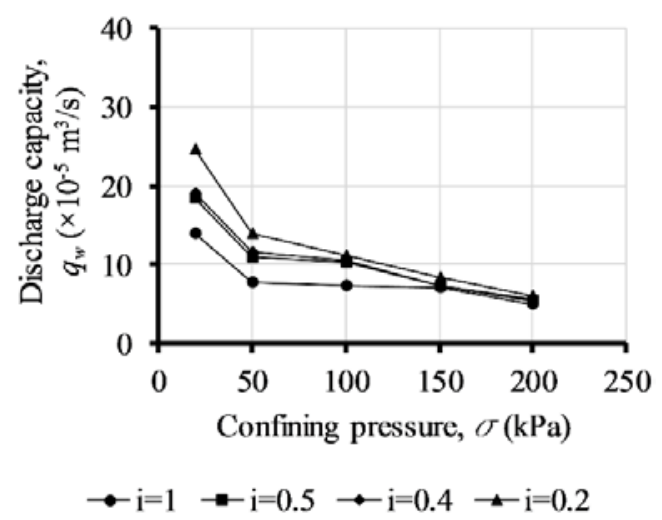

(a) PVD-T3

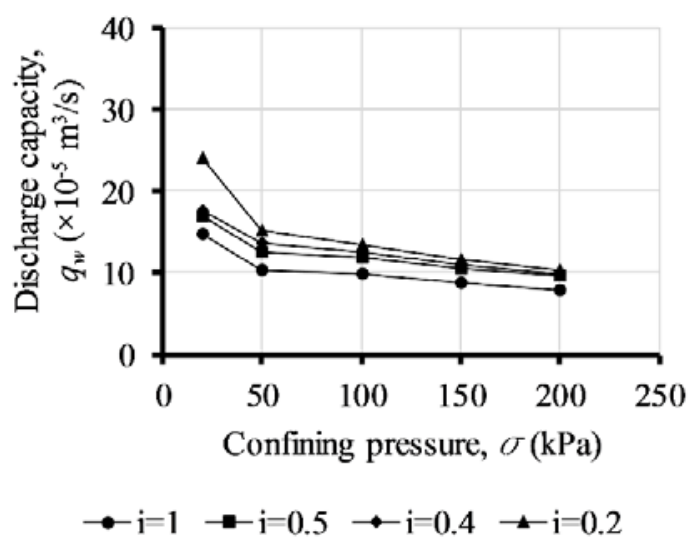

(b) PVD-T4

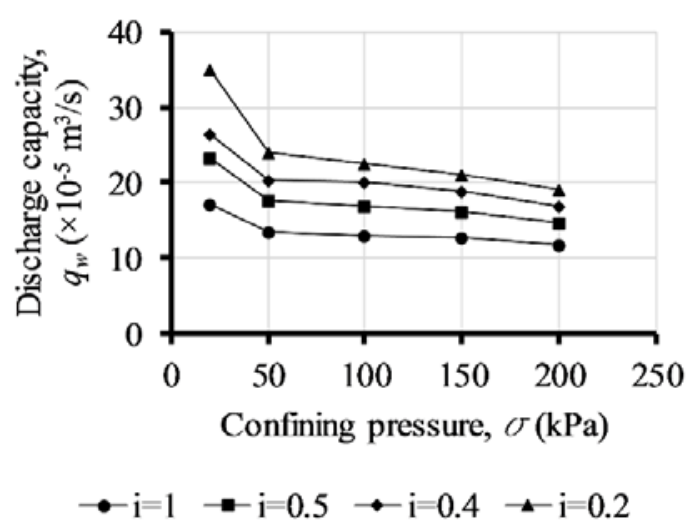

(c) PVD-T5

Fig.5 Decrease in discharge capacity with confining pressure

It can be concluded that at the confining pressure of $200 \mathrm{kPa}$ or approximately equal to the lateral earth pressure at $30 \mathrm{~m}$ depth, the PVD was still capable of maintaining the flow inside the drains. However, the performance decreased significantly since the value of discharge capacity reduction is considerable. The test results show that PVD with greater thickness has a lower reduction, which indicates that thicker PVD has better resistance to confining pressure.

However, this study had not considered the effect of PVD deformation, surrounding soil condition, and clogging, which mentioned as the factors affecting discharge capacity by $[11,12]$, hence the reduction occurred in the field might be more extensive. The reduction of discharge capacity under incremental confining pressure is due to the reduction of PVD thickness, which discussed in the next chapter of this paper.

\subsection{Influence of Incremental Confining Pressure on Transmissivity}

Fig. 6 shows the relationship between transmissivity and hydraulic gradient. Equation (2) is used to determine the value of PVD's transmissivity. As the hydraulic gradient increases, the transmissivity of PVD decreases. For PVD-T3 and PVD-T4 at high confining pressure, the decrease of transmissivity is slightly developed, confirmed by the curve, which nearly flat. This is not likely to occur for PVD-T5 that all of the decreases are appeared more critical. It can be seen from the experimental results that the transmissivity reduced significantly at the early stage of loading.

The test results show that transmissivity decreases with increasing hydraulic gradients in a similar reduction pattern, which indicated a linear function. The highest value of transmissivity occurred at the lowest hydraulic gradients. This study considers the decrease of PVD thickness as the main factor of transmissivity reduction since the thickness reduced when PVD is subjected to confining pressure. The ratio of $\frac{\theta}{\theta_{0}}$ can be obtained from the experimental results, where $\theta_{0}$ is the transmissivity of PVD when it is subjected to the lowest confining pressure (in this study the lowest confining pressure is $20 \mathrm{kPa}$ ), and $\theta$ is the transmissivity of PVD when it is subjected to incremental confining pressure. Then using Eq. (5), the thickness of PVD at each stage can be calculated. The value of mass per unit area $(\mu)$ and polymer density $(\rho)$ of the drains are obtained from Table 1. Hence the value of $\mu / \rho$ for PVD-T3, PVD-T4, and PVD-T5 are 0.53, 0.58, and $0.69 \mathrm{~mm}$, respectively. The values of $\frac{\theta}{\theta_{0}}$ ratio and thickness due to confining pressure are presented in Table 3. For a given $i=1$ (the value of $i=1$ is commonly used in vertical drain design), the reductions of PVD thickness are presented in Fig. 7. The value of thickness reduction of PVD-T3, PVD-T4, and PVD-T5 at the confining pressure of $200 \mathrm{kPa}$ are $28.76 \%$, 20.12\%, and $11.21 \%$, respectively. 


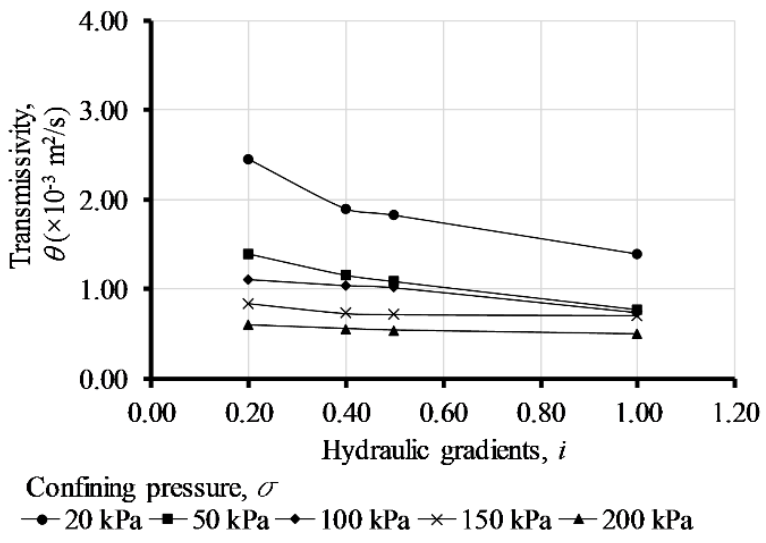

(a) PVD-T3

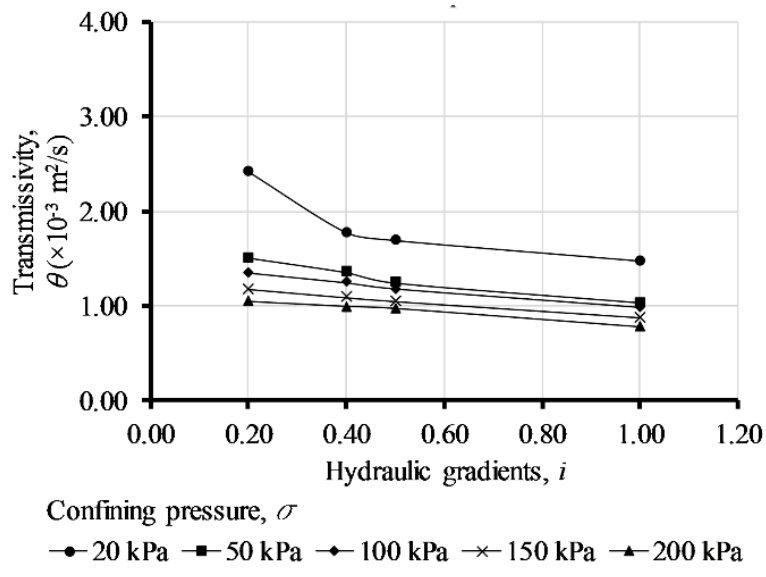

(b) PVD-T4

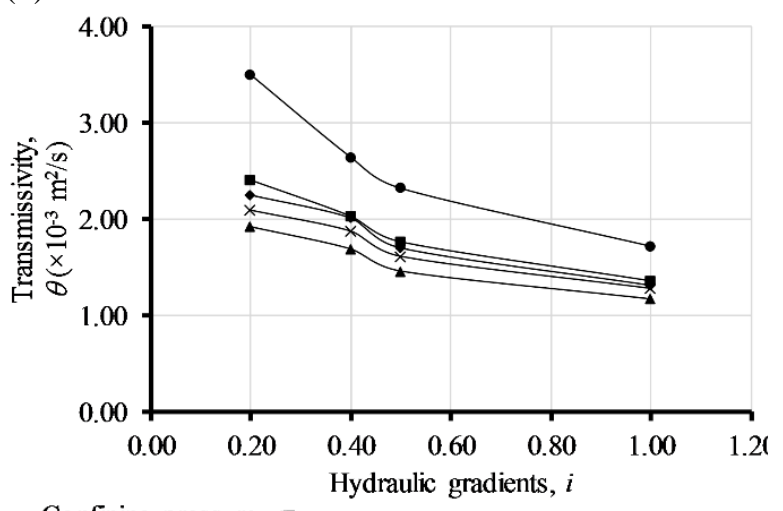

Confining pressure, $\sigma$

$-20 \mathrm{kPa}--50 \mathrm{kPa} \rightarrow 100 \mathrm{kPa} * 150 \mathrm{kPa} \leftarrow 200 \mathrm{kPa}$

\section{(c) PVD-T5}

Fig.6 Variation of transmissivity with hydraulic gradients

It can be concluded that thicker PVD gives more resistance when subjected to confining pressure, which means PVD thickness should be taken as a consideration in vertical drain design. Hansbo stated that the resistance of the PVD core has a critical influence on the effectiveness of PVD in accelerating the consolidation process [18].
Table 3 Values of $\frac{\theta}{\theta_{0}}$ ratio

\begin{tabular}{ccccccc}
\hline $\begin{array}{c}\sigma \\
(\mathrm{kPa})\end{array}$ & \multicolumn{2}{c}{ PVD-T3 } & \multicolumn{2}{c}{ PVD-T4 } & \multicolumn{2}{c}{ PVD-T5 } \\
\cline { 2 - 6 } & $\frac{\theta}{\theta_{0}}$ & $\begin{array}{c}t \\
(\mathrm{~mm})\end{array}$ & $\frac{\theta}{\theta_{0}}$ & $\begin{array}{c}t \\
(\mathrm{~mm})\end{array}$ & $\frac{\theta}{\theta_{0}}$ & $\begin{array}{c}t \\
(\mathrm{~mm})\end{array}$ \\
\hline 20 & 1.00 & 3.00 & 1.00 & 4.00 & 1.00 & 5.00 \\
50 & 0.55 & 2.61 & 0.71 & 3.60 & 0.79 & 4.67 \\
100 & 0.53 & 2.58 & 0.67 & 3.54 & 0.76 & 4.63 \\
150 & 0.51 & 2.56 & 0.60 & 3.43 & 0.74 & 4.59 \\
200 & 0.35 & 2.33 & 0.53 & 3.33 & 0.68 & 4.48 \\
\hline
\end{tabular}

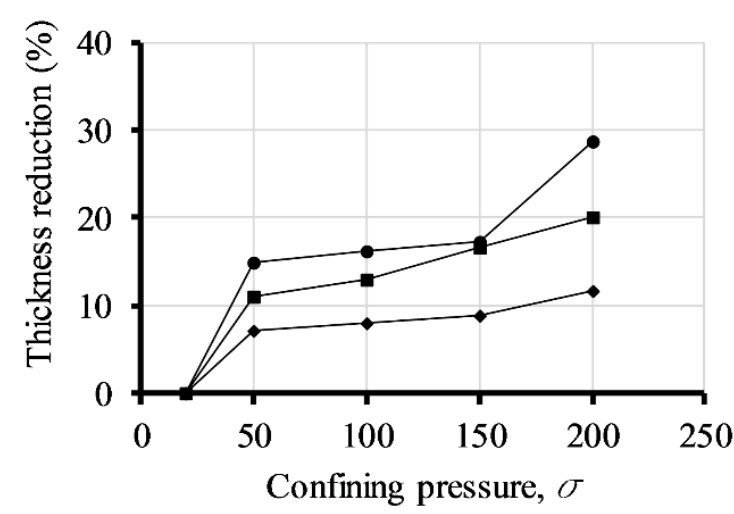

$\bullet$ PVD-T3 $\rightarrow$ PVD-T4 $\rightarrow$ PVD-T5

Fig.7 Decrease of PVD thickness with confining pressure at $i=1$

\section{CONCLUSIONS}

Prefabricated vertical drain (PVD) is working as drainage in a soil improvement project, which accelerates consolidation time. Hydraulic properties, i.e., discharge capacity and transmissivity, are the most critical parameter which controls the performance of PVD. This study conducted a test using a newly designed apparatus adopting ASTM D4716 to measure the discharge capacity and transmissivity. A calibration test was conducted to prove that the apparatus is reliable to be used as a test device.

The test result showed that the reduction of discharge capacity under incremental confining pressure is greater for lower hydraulic gradients, which agreeable with [13]. For PVD-T3, PVD-T4, and PVD-T5, the maximum values of discharge capacity reduction under incremental confining pressure from 20 to $200 \mathrm{kPa}$ are $75.71 \%$, 56.93\%, and $45.25 \%$, respectively. It can be assumed that PVD at a lateral earth pressure more than $200 \mathrm{kPa}$ is still working, although the performance is decreased significantly. It is also found that PVD 
with a greater thickness has a higher value of discharge capacity, which means thicker PVD gives more resistance to the confining pressure.

Based on the test result, the transmissivity decreased when hydraulic gradient increased. The transmissivity reduced significantly in the early stage of loading, then slightly reduced in the next step of loading in the linear pattern. At the lowest hydraulic gradient, the maximum value of transmissivity occurred. PVD thickness holds an important role in transmissivity, as it controls the drainage area of PVD. Under a hydraulic gradient of 1 , the value of thickness reduction of PVD-T3, PVD-T4, and PVD-T5 at the confining pressure of $200 \mathrm{kPa}$ are $28.76 \%, 20.12 \%$, and $11.21 \%$, respectively.

\section{ACKNOWLEDGEMENTS}

The authors would like to express their appreciation to the Soil Mechanics Laboratory of Gadjah Mada University for supporting the experimental work. Great gratitude is also given to the Ministry of Research, Technology, and Higher Education of the Republic of Indonesia for the financial contribution. The authors would also like to acknowledge PT. Teknindo Geosistem Unggul for their technical support in this research.

\section{REFERENCES}

[1] Arulrajah A., Nikraz H., and Bo M. W., Observational method of assessing improvement of marine clay. Ground Improvement, vol. 8, 2004, pp. 151-169.

[2] Chu J., Bo M. W., and Choa V., Practical considerations for using vertical drains in soil improvement projects. Geotextile and Geomembranes vol. 22, no. 1-2, 2004, pp. 101117.

[3] Nagahara H., Fujiyama T., Ishiguro T., and Ohta H., FEM analysis of high airport embankment with horizontal drains. Geotextile and Geomembranes, vol. 22, no. 1-2, 2004, pp. 4962.

[4] Di Filippo G., Bandini V., Cascone E., and Biondi G., Measurements and predictions of settlements induced by preloading and vertical drains on a heterogeneous soil deposit. Measurement, vol. 104, 2017, pp. 302-315.

[5] Cascone E. and Biondi G., A case study on soil settlements induced by preloading and vertical drains. Geotextile and Geomembranes, vol. 38, 2013, pp. 51-67.

[6] Hansbo S., Aspects of vertical drain design : Darcian or non-Darcian flow. Geotechnique, vol. 47, no. 5, 1997, pp. 983-992.

[7] Indraratna B. and Chu J., Ground Improvement: Case Histories. London: Elsevier Ltd, 2005.
[8] Indraratna B. B. and Redana I. W., Plane strain modeling of smear effects associated with vertical drains. Journal of Geotechnical and Geoenvironmental Engineering, no. May, 1997, pp. 474-478.

[9] Bo M. W., Choa V., and Wong K. S., Reclamation and soil improvement on ultra-soft soil. Ground Improvement, vol. 9, no. 1, 2005, pp. 23-31.

[10] Bo M. W., Discharge capacity of prefabricated vertical drain and their field measurements. Geotextile and Geomembranes, vol. 22, no. 1-2, 2004, pp. 37-48.

[11] Holtz R. D., Preloading with prefabricated vertical strip drains. Geotextile and Geomembranes, vol. 6, no. 1-3, 1987, pp. 109131.

[12] Shin E. C., Nazarova Z., Cho K. Y., Kim S. H., and Kang J. K., Evaluation of discharge capacity with various vertical drain core types. in Proceedings of the 4th Asian Regional Conference on Geosynthetics, 2008, pp. 420427.

[13] Bo M. W., Arulrajah A., Horpibulsuk S., Chinkulkijniwat A., and Leong M., Laboratory measurements of factors affecting discharge capacity of prefabricated vertical drain materials. Soils and Foundation, vol. 56, no. 1, 2016, pp. 129-137.

[14] Bergado D. T., Manivannan R., and Balasubramaniam A. S., Proposed criteria for discharge capacity of prefabricated vertical drains. Geotextile and Geomembranes, vol. 14, no. 9, 1996, pp. 481-505.

[15] Chai B. J. and Miura N., Investigation of factors affecting vertical drain behaviour. Journal of Geotechnical and Geoenvironmental Engineering. vol. 125, no. March, 1999, pp. 216-226.

[16] Ali F. H., The influence of filter jacket and core geometry on the longitudinal permeability of prefabricated drain, Soils Foundation, vol. 31, no. 3, 1991, pp. 120-126.

[17] ASTM, Standard Test Method for Determining the (In-Plane) Flow Rate per Unit Width and Hydraulic Transmissivity of Geosynthetic Using A Constant Head. West Conshohocken, PA, USA: ASTM International, 2008.

[18] Hansbo S., Consolidation of Clay By BandShaped Prefabricated Drains. Ground Engineering, vol. 12, no. 5, 1979, pp. 16-18.

[19] Giroud J. P. and Perfetti J., Classification des textiles etmesure de leurs propriétés en vue de leur utilisation en géotechnique, in Proceedings of the International Conference on the Use of Fabrics in Geotechnics, 1977, pp. 345-352.

[20] Giroud J. P., Zhao A., and Richardson G. N., Effect of thickness reduction on geosynthetics 
hydraulic transmissivity,” vol. 7, no. August 2000, 2001, pp. 433-452.

[21] Koerner R. M., Designing with Geosynthetics, 5th ed. New Jersey: Pearson Prentice Hall, 2005.

[22] ASTM, Standard Test Method for Measuring the Nominal Thickness of Geosynthetics 1, no. March 2000. West Conshohocken, PA, USA: ASTM International, 2000.

[23] ASTM, Standard Test Method for Measuring Mass per Unit Area of Geotextiles. West Conshohocken, PA, USA: ASTM International, 1996.

[24] Rixner J. J., Kraemer S. R., and Smith A. D.,
Prefabricated Vertical Drains, Massachusetts: Federal Highway Administration, 1986.

[25] Chai J., Miura N., and Nomura T., Effect of hydraulic radius on long-term drainage capacity of geosynthetics drains. vol. 22, 2004 pp. 3-16.

[26] Miura N. and Chai J.C., Discharge Capacity of Prefabricated Vertical Drains Confined in Clay. Geosynthetic International, vol. 7, no. 2, 2015,pp. 119-135.

Copyright (C) Int. J. of GEOMATE. All rights reserved, including the making of copies unless permission is obtained from the copyright proprietors. 